\title{
DEVELOPING INFORMED CITIZENS: EXPLORING UNIVERSITY STUDENTS' NEWS CONSUMPTION HABITS, BELIEFS, AND RELATED INFORMATION SKILLS
}

\author{
Vanessa Dennen, Lauren Bagdy and Yujin Park \\ Florida State University, Tallahassee, FL USA
}

\begin{abstract}
The internet age has transformed how we access and consume information, including current events. In this survey of 598 traditional university students who are coming of age and newly able to participate in civic activities such as voting, we explore knowledge and interest levels in current events across different contexts (e.g., local news, national news, sports, entertainment), sources of information about those current events, and perceived accuracy of those sources. We also consider the role political ideology plays in news interests and behaviors. Findings show that interest in current events is greatest at the national level, followed by the international level. Local news interest is lowest. Students rated their knowledge levels lower than their interest levels for most current events areas. Discrepancies between access habits and perceptions of accuracy suggest that students knowingly rely on less accurate current events sources. Implications for information literacy education in the university curriculum are discussed.
\end{abstract}

\section{KEYWORDS}

Current Events, Digital Literacy, Information Access, Information Skills, Online Information, University Students

\section{INTRODUCTION}

A democratic society depends on well-informed citizens with strong critical thinking skills to form a voter base that elects leaders who will develop solutions to societal challenges. Individual citizens have many ways to stay well informed. Traditional print and broadcast news media now compete with the internet for audience and influence. The internet has been a disrupter in this area, providing individuals with more options for accessing information sources and the opportunity to share information to their networks. Web pages and social media provide platforms for hosting and sharing current events and opinions, decentralizing information access. Simultaneously, they are spaces where one can find news and misinformation and where viewpoints can be shared and manipulated (Ferrara et al., 2020).

University students are a voting population of great interest. Traditional-aged university students are usually first eligible to vote during their university years. Given the widespread influence of social media, it is vital to promote the development of online information searching and literacy skills to identify accurate information and dismiss inaccurate sources while also distinguishing between fact and opinion. In other words, today's youth's digital literacy skills will likely have a lasting effect on our society. Their current events consumption behaviors, including reading online sources and fact-checking with online sources, affect the type and accuracy of the information they share with their online networks. It may also shape their voting behaviors. This study explores how university students access news and learn about current events. It asks about their self-reported interests, knowledge, and ability to use information literacy skills to discern the information they encounter online accurately. 


\section{BACKGROUND}

Teens and young adults are heavy social media (Anderson and Jiang, 2018). They use social media as a resource to acquire information for course assignments (Kim et al., 2014) and use it as a major source of news (Head and Eisenberg, 2011, Tang and Oh, 2020). Among the reasons youth give for consuming news via social media and online sources over traditional media are preferences for multimedia, control and personalization, and brevity (Huang, 2009).

University students, as heavy users of social media, must be able to discern the accuracy and credibility of information found online. However, prior research suggests that university students do not have proficient information literacy skills and often have inflated confidence in their ability to critically assess information (Gustavson and Nall, 2011, Gross and Latham, 2012), a noted problem in the general population as well (Mahmood, 2016).

Voting is a behavior that has increased among college-age students in recent years (Institute for Democracy in Higher Education, 2018). As new voters, university students are challenged to learn about current events at the local, state, national, and even world levels to be informed voters. Discerning accurate information can be a challenge, and first-time voters can be particularly emboldened by information found on social media, which can solidify their certainty about how they will vote (Ohme et al., 2018). Additionally, social media fosters a participatory culture, allowing young adults to engage in political discourse directly. The ability to practice being political may be important for developing politically engaged youth, although more research is needed to support this assertion (Wray-Lake, 2019).

When people seek information online, their political ideologies can influence what they search for and read. For example, one study found Republicans were more likely than Democrats to engage in selective avoidance of sources that would challenge their beliefs (Garrett and Stroud, 2014). The spread of misinformation and "fake news" on social media is a concern for voters regardless of ideology, especially after the well-documented effects of fake news on the 2016 United States presidential election (Allcott and Gentzkow, 2017). Given the influence that social media can have over young voters (Ohme et al., 2018), it is important to ensure that they access and make decisions using accurate resources, regardless of their political belief system.

\subsection{Research Purpose and Questions}

The purpose of this research is to investigate university students' current events and information-seeking beliefs and activities with a primary focus on how they use the internet to support this endeavor. A secondary purpose is to examine how these online activities and beliefs relate to their political ideologies. The research questions that guided this study are:

1. How interested and knowledgeable are university students about current events at different levels?

2. How do university students access information about current events?

a. How much do they use online resources versus word of mouth or traditional resources to learn about current events?

b. How do they perceive the accuracy of these resources?

3. How do university students perceive their ability to locate and assess the quality of online current events information?

4. Do online information habits, beliefs, and skills differ by political ideology?

The answers to these questions can help university faculty better understand how their students engage with information resources about current events and identify opportunities for improving student knowledge and abilities in this area. 


\section{METHOD}

\subsection{Participants}

Participants in this study are 598 students enrolled at a large public university in the United States. Students were recruited for the study from a college-level research participation pool through which students complete research studies of their choice to earn points in their classes. Study participation is optional and voluntary. Participants in the study pool can participate in studies of their choice or opt out and complete an alternate assignment designated by their course instructor. The study was conducted with approval from the researchers' Institutional Review Board, and all participants consented to participate.

\subsection{Data Collection}

The study used an online survey to collect data. The survey items reported here come from a larger survey of university students' information-seeking behaviors and information literacy skills in various online contexts (see Dennen et al., 2020 for additional findings). This study asked a combination of Likert-style, multiple response, and open-ended items to ask about demographics, interest level in and level of knowledge about current events; use of social media as a source of information about current events; social media as a source of school-related information; and how, when, and from whom the students learned about using social media tools to find information. To measure social media as a source for school-related information, the researchers used a validated scale, the Information Competency Assessment Instrument (Marshall, 2006). The researchers made minor modifications to the scale to fit the study context.

\subsection{Data Analysis}

Data analysis was conducted using SPSS. Frequency distributions were generated for all closed items. Chi-square Goodness of Fit tests were used to determine if students with different political ideologies had different habits and beliefs related to current events information sources.

\section{FINDINGS}

\subsection{Participant Overview}

This study had 598 participants, of whom 453 (75.8\%) were female. The remainder were male, with the exception of two who reported they were non-binary and one who declined to provide gender identification information. Table 1 presents the class standing of the students. The disproportionate number of female participants is representative of the study pool demographics from which they were recruited. The majority of the participants $(428 ; 71.6 \%$ ) had upperclass standing (see Table 1). Although we did not explicitly ask about age, based on past studies with this population, the majority of the participants - and probably all of the undergraduate ones - likely were between the ages 18-22.

Table 1. Class standing of participants

\begin{tabular}{lll}
\hline Class Standing & Frequency & Percent \\
\hline Sophomore & 111 & 18.6 \\
Junior & 218 & 36.5 \\
Senior & 210 & 35.1 \\
Graduate Student & 16 & 2.7 \\
Total & 598 & 100.0 \\
\hline
\end{tabular}


The majority of the participants $(515 ; 86.1 \%)$ reported that they were registered to vote. Those who had not gotten around to doing so $(47 ; 7.9 \%)$ were not eligible to vote in the United States $(20 ; 3.3 \%)$ or were not interested in voting $(13 ; 2.2 \%)$. When asked to classify their political ideologies, conservative, moderate, and liberal viewpoints were all well represented in the sample (see Table 2).

Table 2. Political ideologies of participants

\begin{tabular}{lll}
\hline Class Standing & Frequency & Percent \\
\hline Moderate & 177 & 29.6 \\
Liberal & 285 & 30.9 \\
Uncertain & 92 & 15.4 \\
Total & 598 & 100.0 \\
\hline
\end{tabular}

\subsection{Current Events Interest and Knowledge}

When asked about their interest in current events, national news, world news, and entertainment news were the highest rated topical areas, and local news was the lowest (see Table 3). Interest in sports news was split, with similar numbers of participants expressing low (38.1\%) and high (36.1\%) interest. Students consistently rated their knowledge levels in each area lower than their interest levels (i.e., more students reported high interest in an area than high knowledge; see Table 3).

Table 3. Current events interest levels

\begin{tabular}{lllllllll}
\hline Level & General & Campus & Local & State & National & World & Sports & Entertainment \\
\hline Low & 78 & 155 & 205 & 126 & 62 & 98 & 228 & 134 \\
& $13.0 \%$ & $25.9 \%$ & $34.3 \%$ & $21.1 \%$ & $10.4 \%$ & $16.4 \%$ & $38.1 \%$ & $22.4 \%$ \\
& & & & & & & & \\
Med. & 265 & 225 & 244 & 240 & 200 & 203 & 154 & 178 \\
& $44.3 \%$ & $37.6 \%$ & $40.8 \%$ & $40.1 \%$ & $33.4 \%$ & $33.9 \%$ & $25.8 \%$ & $29.8 \%$ \\
\multirow{2}{*}{ High } & 255 & 218 & 149 & 232 & 336 & 297 & 216 & 286 \\
& $42.6 \%$ & $36.5 \%$ & $24.9 \%$ & $38.8 \%$ & $56.2 \%$ & $49.7 \%$ & $36.1 \%$ & $47.8 \%$ \\
& & & & & & & & \\
Total & 598 & 598 & 598 & 598 & 598 & 598 & 598 & 598 \\
& $100.0 \%$ & $100.0 \%$ & $100.0 \%$ & $100.0 \%$ & $100.0 \%$ & $100.0 \%$ & $100.0 \%$ & $100.0 \%$ \\
\hline
\end{tabular}

Table 4. Current events knowledge levels

\begin{tabular}{lllllllll}
\hline Level & General & Campus & Local & State & National & World & Sports & Entertainment \\
\hline Low & 113 & 219 & 289 & 216 & 147 & 219 & 285 & 200 \\
& $18.9 \%$ & $36.6 \%$ & $48.3 \%$ & $36.1 \%$ & $24.6 \%$ & $36.6 \%$ & $47.7 \%$ & $33.4 \%$ \\
& & & & & & & & \\
Med. & 343 & 251 & 231 & 285 & 284 & 258 & 149 & 213 \\
& $57.4 \%$ & $42.0 \%$ & $38.6 \%$ & $47.7 \%$ & $47.5 \%$ & $43.1 \%$ & $24.9 \%$ & $35.6 \%$ \\
& & & & & & & & \\
High & 142 & 128 & 78 & 97 & 167 & 121 & 164 & 185 \\
& $23.7 \%$ & $21.4 \%$ & $13.0 \%$ & $16.2 \%$ & $27.9 \%$ & $20.2 \%$ & $27.4 \%$ & $30.9 \%$ \\
& & & & & & & & \\
Total & 598 & 598 & 598 & 598 & 598 & 598 & 598 & 598 \\
& $100.0 \%$ & $100.0 \%$ & $100.0 \%$ & $100.0 \%$ & $100.0 \%$ & $100.0 \%$ & $100.0 \%$ & $100.0 \%$ \\
\hline
\end{tabular}

\subsection{Current Events Sources and Accuracy}

Students indicated that they more frequently relied on online information sources or people they knew, specifically parents or close friends, than traditional news sources to obtain information about current events (see Table 5). Social media was the most frequently consulted source, although web sites, parents, and close friends were consulted often or sometimes by around $85 \%$ of the participants. 
Table 5. Frequency of Potential Sources of Information about Current Events

\begin{tabular}{llllll}
\hline Category & News Source & \multicolumn{3}{c}{ Frequency } \\
\hline \multirow{2}{*}{$\begin{array}{l}\text { Traditional } \\
\text { Sources }\end{array}$} & TV news & Often & Sometimes & Seldom & Never \\
\cline { 2 - 5 } & Newspapers & $56(9.4 \%)$ & $106(17.7 \%)$ & $191(26.9 \%)$ & $85(14.2 \%)$ \\
& Radio & $52(8.7 \%)$ & $166(27.8 \%)$ & $208(34.8 \%)$ & $246(41.1 \%)$ \\
Online & Web sites & $248(41.5 \%)$ & $254(42.5 \%)$ & $74(12.4 \%)$ & $22(3.7 \%)$ \\
Sources & Social media & $376(62.9 \%)$ & $156(26.1 \%)$ & $45(7.5 \%)$ & $21(3.5 \%)$ \\
\multirow{2}{*}{ People } & & & & & \\
& Parents & $273(45.7 \%)$ & $228(38.1 \%)$ & $66(11.0 \%)$ & $31(5.2 \%)$ \\
& Close friends & $249(41.6 \%)$ & $260(43.5 \%)$ & $73(12.2 \%)$ & $16(2.7 \%)$ \\
\hline
\end{tabular}

When asked about their perceived accuracy of various information sources, the participants demonstrated skepticism. They were most likely to consider traditional sources and parents highly accurate than social media or friends (see Table 6). Additionally, social media was the source deemed inaccurate by the largest group of participants $(79 ; 13.2 \%)$.

Table 6. Accuracy of Potential Sources of Information about Current Events

\begin{tabular}{lllll}
\hline Category & News Source & \multicolumn{3}{c}{ Accuracy } \\
\hline \multirow{2}{*}{$\begin{array}{l}\text { Traditional } \\
\text { Sources }\end{array}$} & TV news & Highly Accurate & Moderately Accurate & Not Accurate at All \\
\cline { 2 - 4 } & Newspapers & $257(31.3 \%)$ & $368(61.5 \%)$ & $43(7.2 \%)$ \\
& Radio & $122(20.4 \%)$ & $313(52.3 \%)$ & $34(5.7 \%)$ \\
Online & Web sites & $120(20.1 \%)$ & $426(71.2 \%)$ & $50(8.4 \%)$ \\
Sources & Social media & $64(10.7 \%)$ & $452(75.6 \%)$ & $26(4.4 \%)$ \\
& & & $455(76.1 \%)$ & $79(13.2 \%)$ \\
People & Parents & $211(35.3 \%)$ & $356(59.5 \%)$ & $31(5.2 \%)$ \\
& Close friends & $80(13.4 \%)$ & $485(81.1 \%)$ & $33(5.5 \%)$ \\
\hline
\end{tabular}

\subsection{Information Searching and Assessment Abilities}

Students indicated their agreement with statements about searching for and assessing the accuracy of information on web sites and via social media. Overall, they reported the highest confidence in their ability to distinguish from news and opinion, yet lowest confidence in their ability to spot errors in information from news media and social media (Table 7).

Table 7. Student information abilities

\begin{tabular}{lccc}
\hline Item & Disagree & Moderate & Agree \\
\hline $\begin{array}{l}\text { I know the difference } \\
\text { between news and opinion. }\end{array}$ & $7(1.2 \%)$ & $31(5.2 \%)$ & $560(93.6 \%)$ \\
$\begin{array}{l}\text { I understand how to use } \\
\text { search engines to find } \\
\text { information. }\end{array}$ & $9(1.5 \%)$ & $20(3.3 \%)$ & $569(95.2 \%)$ \\
$\begin{array}{l}\text { I can tell when information is } \\
\text { biased. }\end{array}$ & $29(4.8 \%)$ & $57(9.5 \%)$ & $512(85.6 \%)$ \\
$\begin{array}{l}\text { I am good at searching for } \\
\text { information on social media } \\
\text { sites. }\end{array}$ & $32(5.4 \%)$ & $59(9.9 \%)$ & $507(84.8 \%)$ \\
$\begin{array}{l}\text { I can confidently spot } \\
\text { inaccuracy, errors, etc. in the } \\
\text { information from social } \\
\text { media. }\end{array}$ & $64(10.7 \%)$ & $94(15.7 \%)$ & $440(73.6 \%)$ \\
$\begin{array}{l}\text { I can confidently spot } \\
\text { inaccuracy, errors, etc. in the } \\
\text { information from news } \\
\text { media. }\end{array}$ & $84(14.0 \%)$ & $408(18.1 \%)$ & $406(67.9 \%)$ \\
\hline
\end{tabular}




\subsection{Political Ideologies and Current Events}

We examined the data to see if there were any differences based on political ideology. Across many dimensions, participants were similar in their beliefs regardless of ideology. However, Chi-square Goodness of Fit tests yielded certain areas where groups had significant differences compared to the overall study population. Findings are discussed below, and full data tables can be found at http://bit.ly/ES20201data.

\subsubsection{Conservative Students}

Students with conservative political beliefs were more likely than students with other ideologies to believe that their parents were a highly accurate source of information. In contrast, moderate and liberal students were more likely to believe that their parents were a moderately accurate source or not accurate at all. Conservative students were also more likely to report using television as a source of information about current events. In terms of current events interests, the conservative students differed from the overall group in one interesting way. They were more likely to be interested in and knowledgeable about sports. Compared to other groups, they were less likely to feel that social media was an accurate information source and more likely to believe they could spot inaccuracies.

\subsubsection{Liberal Students}

Liberal students were more likely to agree that they were adept at using search engines to find information and identify biased information. They also reported used web sites for current events information with greater frequency than other groups. They were most likely to differ from other groups in terms of sports interests and knowledge. Although just as likely as other groups to be highly interested in sports, the percentage of liberal students who reported being uninterested in sports was greater than other groups.

\subsubsection{Uncertain Student Beliefs}

The students who identified as politically uncertain were less likely to be interested in and knowledgeable about current events at the national and global level than other students. They also reported being less confident of their ability to identify biased information than other groups and less confident of their skills overall.

\section{DISCUSSION AND CONCLUSION}

These findings show that university students are likely to be registered to vote and seek information related to current events from online sources, despite skepticism about accuracy. In response to our first research question, national and world events are of greater interest to university students than local and state current events. This finding may reflect the relative volume of information available online and the frequency with which it is shared on social media. In other words, there may be a relationship between exposure and interest.

It is not surprising that traditional media play a lesser role in exposing university students to current events than people or online sources. The former typically requires more focused attention (Huang, 2009) and deliberate media seeking behavior, whereas encounters with current events via personal networks, whether family and friends or on social media, can be unplanned, incidental, brief, and tailored directly to the individual (Boczkowski et al., 2018). Curated news appeals to a sub-set of teenagers (Edgerly et al., 2018). However, the decreased access of traditional news media is concerning; other research shows that individuals who count on incidental news exposure to keep them informed are less knowledgeable about (Gil de Zúñiga et al., 2017) and less likely to participate in political matters than peers who access traditional news (Edgerly et al., 2018).

Parents play an interesting role in university student information habits. The students in this study generally trust their parents, particularly when their ideologies lean more to the conservative side. However, it would be a mistake to assume that the relationship is unilateral, with parents imparting their knowledge and views to their children. Parent-child dyads have a more complex approach to discussions around topics like news and politics, and information and viewpoints can trickle up in addition to trickling down (York, 2019).

The students in this study feel confident that they can spot the inaccuracies, mirroring findings from other studies of information literacy among college students (Gustavson and Nall, 2011, Gross and Latham, 2012). Although they generally feel that traditional news resources are trustworthy, they do not access these sources with regularity and our findings show that they do not unilaterally believe in the accuracy of these sources. 
This study did not directly ask about fake news, but some students may be suspicious that mainstream media promotes fake news, a viewpoint increasingly held by conservatives (van der Linden et al., 2020).

The differences in beliefs and activities based on political ideology suggest that students may develop skill confidence in areas related to their typical practices. Students with liberal beliefs use web sites more than others and become confident users in assessing them as information sources. Conservative students believe social media is likely to be inaccurate and have greater confidence than their peers that they can spot the inaccuracies. The parent-related findings may reflect the broadening exposure to new ideas and idealism that many university students experience.

\subsection{Limitations}

A major limitation of this study was the sampling approach. The participants were sampled from a college's research participation pool with a gender imbalance. A study conducted on the general population of university students might yield different findings. At the same time, this particular sample may be of interest because of the high incidence of students with education-related majors. Presumably, they will go on to teach current events and information literacy skills to subsequent generations.

\subsection{Implications and Future Research}

These findings have implications for how universities address information literacy skills across the curriculum. Most disciplines have a direct connection to current events and are affected by policies developed and enacted at some level(s). Instructors should seize the opportunity to explore current events and compare and contrast what is reported by different outlets and across different electronic media, helping students differentiate fact and opinion and identify biases in different information resources. These baseline skills can be developed and practiced without delving into personal ideologies, which could be a minefield for classroom exploration. Still, the information skills developed in a course might serve these young adult citizens well as they purposefully seek or incidentally encounter information that might shape their voting decisions. Additionally, increased civic education experiences may lead to increased participation in voting (Siegel-Stechler, 2019).

Future research might explore the specific current events resources that students read and subscribe to online to see if they are building an echo chamber of knowledge sources, joining the ranks of citizens who do not believe news sources that tilt in a direction that would challenge their political beliefs (van der Linden et al., 2020). Additionally, future research should develop and test specific instructional interventions' effectiveness to help develop information literacy skills in various current events areas. In such studies, it will be essential to look at the immediate effects of information literacy instruction and consider the long-term effects on information access and voting behaviors.

\section{REFERENCES}

Allcott, H. \& Gentzkow, M. 2017. Social media and fake news in the 2016 election. Journal of economic perspectives, 31 , 211-36.

Anderson, M. \& Jiang, J. 2018. Teens, social media \& technology 2018, Washington, D.C., Pew Research.

Boczkowski, P. J., Mitchelstein, E. \& MatassI, M. 2018. "News comes across when I'm in a moment of leisure": Understanding the practices of incidental news consumption on social media. New Media \& Society, 20, 3523-3539.

Dennen, V. P., Bagdy, L. M. \& Park, Y. 2020. Student beliefs about information literacy skills: Search engines, social media, and assessing accuracy. American Educational Research Association [Online]. Available: http://bit.ly/AERA20-DennenBagdyPark.

Edgerly, S., Vraga, E. K., Bode, L., Thorson, K. \& Thorson, E. 2018. New media, new relationship to participation? A closer look at youth news repertoires and political participation. Journalism \& Mass Communication Quarterly, 95, 192-212.

Ferrara, E., Chang, H., Chen, E., Muric, G. \& Patel, J. 2020. Characterizing social media manipulation in the 2020 US presidential election. First Monday.

Garrett, R. K. \& Stroud, N. J. 2014. Partisan paths to exposure diversity: Differences in pro- and counterattitudinal news consumption. Journal of Communication, 64, 680-701. 
Gil De Zúñiga, H., Weeks, B. \& Ardèvol-Abreu, A. 2017. Effects of the news-finds-me perception in communication: Social media use implications for news seeking and learning about politics. Journal of Computer-Mediated Communication, 22, 105-123.

Gross, M. \& Latham, D. 2012. What's skill got to do with it?: Information literacy skills and self-views of ability among first-year college students. Journal of the American Society for Information Science and Technology, 63, 574-583.

Gustavson, A. \& Nall, H. C. 2011. Freshman overconfidence and library research skills: a troubling relationship? College \& Undergraduate Libraries, 18, 291-306.

Head, A. \& Eisenberg, M. 2011. How college students use the Web to conduct everyday life research. First Monday, 16.

Huang, E. 2009. The causes of youths' low news consumption and strategies for making youths happy news consumers. Convergence: The International Journal of Research into New Media Technologies, 15, 105-122.

Institute for Democracy in Higher Education. 2018. 2018 national study of learning, voting, and engagement (NSLVE) national data. Available: https://idhe.tufts.edu/nslve.

Kim, K.-S., Sin, S.-C. J. \& Yoo-Lee, E. Y. 2014. Undergraduates' use of social media as information sources. College \& research libraries, $75,442-457$.

Mahmood, K. 2016. Do people overestimate their information literacy skills? A systematic review of empirical evidence on the Dunning-Kruger effect. Communications in Information Literacy, 10, 3.

Ohme, J., De Vreese, C. H. \& Albaek, E. 2018. The uncertain first-time voter: Effects of political media exposure on young citizens' formation of vote choice in a digital media environment. New Media \& Society, 20, 3243-3265.

Siegel-Stechler, K. 2019. Is civics enough? High school civics education and young adult voter turnout. The Journal of Social Studies Research, 43, 241-253.

Tang, R. \& Oh, K. E. 2020. University students' mobile news consumption activities and evaluative/affective reactions to political news during election campaigns: A diary study. Journal of Information Science, 46, 476-495.

Van Der Linden, S., Panagopoulos, C. \& Roozenbeek, J. 2020. You are fake news: Political bias in perceptions of fake news. Media, Culture \& Society, 42, 460-470.

Wray-Lake, L. 2019. How do young people become politically engaged? Child Development Perspectives, 13, 127-132.

York, C. 2019. Is it top-down, trickle-up, or reciprocal?: Testing longitudinal relationships between youth news use and parent and peer political discussion. Communication Studies, 70, 377-393. 